\title{
MR Elastography Can Be Used to Measure Brain Stiffness Changes as a Result of Altered Cranial Venous Drainage During Jugular Compression
}

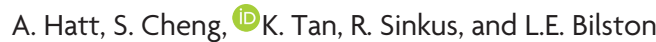

\begin{abstract}
BACKGROUND AND PURPOSE: Compressing the internal jugular veins can reverse ventriculomegaly in the syndrome of inappropriately low pressure acute hydrocephalus, and it has been suggested that this works by "stiffening" the brain tissue. Jugular compression may also alter blood and CSF flow in other conditions. We aimed to understand the effect of jugular compression on brain tissue stiffness and CSF flow.

MATERIALS AND METHODS: The head and neck of 9 healthy volunteers were studied with and without jugular compression. Brain stiffness (shear modulus) was measured by using MR elastography. Phase-contrast MR imaging was used to measure CSF flow in the cerebral aqueduct and blood flow in the neck.

RESULTS: The shear moduli of the brain tissue increased with the percentage of blood draining through the internal jugular veins during venous compression. Peak velocity of caudally directed CSF in the aqueduct increased significantly with jugular compression $(P<.001)$. The mean jugular venous flow rate, amplitude, and vessel area were significantly reduced with jugular compression, while cranial arterial flow parameters were unaffected.

CONCLUSIONS: Jugular compression influences cerebral CSF hydrodynamics in healthy subjects and can increase brain tissue stiffness, but the magnitude of the stiffening depends on the percentage of cranial blood draining through the internal jugular veins during compression - that is, subjects who maintain venous drainage through the internal jugular veins during jugular compression have stiffer brains than those who divert venous blood through alternative pathways. These methods may be useful for studying this phenomenon in patients with the syndrome of inappropriately low-pressure acute hydrocephalus and other conditions.
\end{abstract}

ABBREVIATIONS: $G^{\prime}=$ shear storage modulus; $G^{\prime \prime}=$ shear loss modulus; $M R E=$ MR elastography; PJVF = percentage jugular venous flow; SILPAH = syndrome of inappropriately low-pressure acute hydrocephalus

C hanges in venous drainage from the cranium, such as reduction in internal jugular vein flow when moving from a supine to upright posture, can alter cerebral hemodynamics and CSF dynamics. ${ }^{1}$ However, postural changes are difficult to study by

Received October 8, 2014; accepted after revision March 3, 2015.

From Neuroscience Research Australia (A.H., S.C., K.T., L.E.B.), Randwick, New South Wales, Australia; School of Mechanical Engineering (S.C.), Macquarie University, North Ryde, New South Wales, Australia; School of Medical Sciences (S.C.) and Graduate School of Biomedical Engineering (K.T.), University of New South Wales, Kensington, New South Wales, Australia; British Heart Foundation Centre of Excellence (R.S.), Division of Imaging Sciences and Biomedical Engineering, King's College London, King's Health Partners, St. Thomas' Hospital, London, United Kingdom; and Prince of Wales Clinical School (L.E.B.), University of New South Wales, Randwick, New South Wales, Australia.

This research was supported in part by the Ronald Geoffrey Arnott Foundation. Lynne Bilston is funded by a National Health and Medical Research Council fellowship (No. 568610). Ralph Sinkus receives financial support from the UK Department of Health via the National Institute for Health Research Comprehensive Biomedical Research Centre award to Guy's and St Thomas' National Health Service Foundation Trust in partnership with King's College London and King's College Hospital National Health Service Foundation Trust. using brain MR imaging. There is recent clinical interest in understanding how cranial venous outflow affects the brain, in part due to the controversial chronic cerebrospinal venous insufficiency hypothesis. ${ }^{2}$

Reduction in venous outflow through the internal jugular veins, through the use of an elastic bandage (neck wrap), has also been used as a treatment for the syndrome of inappropriately low-pressure acute hydrocephalus (SILPAH), ${ }^{3}$ also known as negative or low-pressure hydrocephalus, rapidly reversing ventriculomegaly and restoring neurologic function. ${ }^{4-8}$ SILPAH is a rare and enigmatic condition in which patients exhibit ventricu-

Paper presented in part in abstract form at: Annual Meeting of the Australia and New Zealand Society of Magnetic Resonance, October 27-30, 2013; Brisbane, Queensland, Australia; and in poster form at: University of New South Wales Brain Sciences Symposium, October 18, 2013; Sydney, New South Wales, Australia. Please address correspondence to Lynne E. Bilston, PhD, Neuroscience Research Australia, Barker St, Randwick, NSW 2031, Australia; e-mail: I.bilston@neura.edu.au - - Indicates open access to non-subscribers at www.ajnr.org

http://dx.doi.org/10.3174/ajnr.A4361 

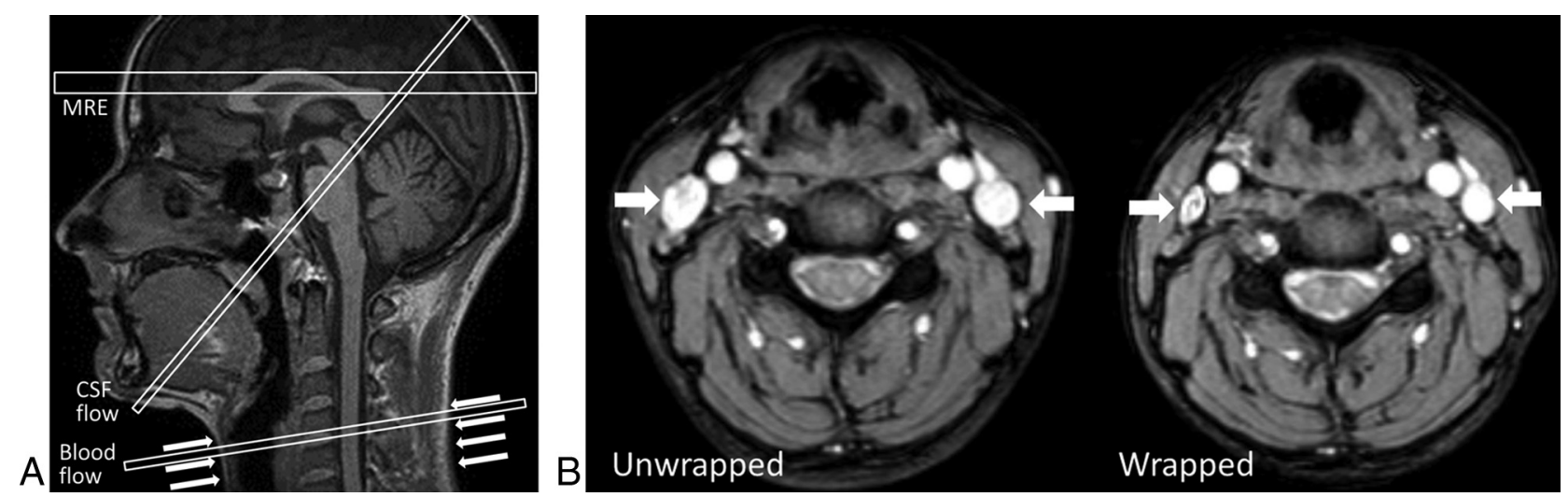

FIG 1. A, Sagittal view of imaging planes for the MRE study within and just above the ventricles, phase-contrast MR imaging CSF flow study of the cerebral aqueduct, and phase-contrast MR imaging flow study of the blood flow in the neck vessels at the level of the compression. The arrows denote the position of neck wrap. B, Images of neck vessels with and without the neck wrap, showing the reduction in internal jugular vein area. Internal jugular veins are indicated by white arrows.

lomegaly and very low intracranial pressure ${ }^{9}$ associated with obstruction to the CSF pathways between the ventricles and the subarachnoid space. Despite low intracranial pressure, symptoms mirror those of high intracranial pressure. ${ }^{4-7,9-12}$ The pathophysiology for SILPAH remains unclear. However, changes in brain stiffness as a result of the loss of extracellular fluid ${ }^{4,8,9,11-13}$ combined with CSF leaks ${ }^{6}$ have been suggested. Jugular compression has also been observed to increase the amplitude of CSF waveforms in the cervical subarachnoid space in subjects whose venous drainage took place primarily through the internal jugular veins and to decrease the amplitudes in subjects with primarily extrajugular drainage. ${ }^{14}$ These changes may be related to alterations in intracranial pressure arising from increased dural venous pressure $^{4}$ and stiffening of brain tissue. ${ }^{4,6,8}$ However, the relationships between cranial venous drainage routes, cerebral CSF flow, and brain tissue properties in the context of jugular compression have not been investigated, to our knowledge.

Viscoelastic tissue response to loading consists of a recoverable elastic component and a nonrecoverable viscous component. The response to shear loading comprises the shear storage $\left(G^{\prime}\right)$ and loss $\left(G^{\prime \prime}\right)$ moduli, representing elastic and viscous components, respectively. Increases in the shear moduli reflect higher stiffness.

MR elastography $(\mathrm{MRE})^{15}$ is a noninvasive imaging technique that measures tissue stiffness by imaging the propagation of mechanical vibration with motion-sensitive gradients. Viscoelastic properties are quantified by analyzing the wave-propagation characteristics. MRE has been used to quantify the viscoelastic properties of healthy in vivo brain tissue ${ }^{16-18}$ and brain disorders such as normal pressure hydrocephalus. ${ }^{19,20}$ The shear moduli obtained depend on the vibration frequency, with lower values obtained at low frequencies.

In this study, we aimed to use MRE to determine the effect of restricting cranial venous outflow by using bilateral jugular compression on brain stiffness and CSF flow in healthy volunteers. We hypothesized that brain viscoelasticity and CSF velocity would increase with jugular compression.

\section{MATERIALS AND METHODS}

Nine healthy volunteers ( 3 women; mean age, $32.6 \pm 10.9$ years) were imaged supine with and without jugular compression. The research was approved by the local Human Research Ethics Committee. Participants gave written informed consent.

Bilateral compression of the internal jugular veins ${ }^{4-8}$ was achieved by fastening an $8-\mathrm{cm}$ wide elastic bandage around the neck (Fig 1) to apply a mild compression, but not impair breathing or comfort. After 1 scan acquisition, the wrap was released while maintaining the head position. After a short pause allowing normal flow to be restored, scans were repeated.

\section{MR Imaging}

Data were acquired by using a 3T MR imaging scanner (Achieva 3T TX; Philips Healthcare, Best, the Netherlands) and a 1-channel transmit-receive neurovascular coil.

Vascular and CSF Flow Studies. Phase-contrast MR imaging was used to measure blood flow through the internal jugular veins and carotid and vertebral arteries at the level of the neck wrap and CSF flow through the cerebral aqueduct. The imaging planes are shown in Fig 1. A single 5-mm-thick section was assessed over 30 cardiac phases and gated retrospectively by using a finger plethysmography sensor. For the vascular flow study, a phase-encoding velocity of $60 \mathrm{~cm} / \mathrm{s}$ was used with FOV $=180 \times 180 \mathrm{~mm}$, matrix $=288 \times 288, \mathrm{TR} / \mathrm{TE}=21 / 5.73 \mathrm{~ms}$, flip angle $=10^{\circ}$. For CSF flow, a phase-encoding velocity of $4 \mathrm{~cm} / \mathrm{s}$ was used, with $\mathrm{FOV}=180 \times 180 \mathrm{~mm}$, matrix $=352 \times 352, \mathrm{TR} / \mathrm{TE}=21 / 10.1$ ms, flip angle $=10^{\circ}$.

MRE. MRE was performed on an axial imaging region within and just above the ventricles (Fig 1). Shear waves were produced in the brain via a purpose-built mechanical transducer consisting of a coaxial coil system and an individually molded polymer mouthguard, ${ }^{16,18}$ triggered by the MR spectrometer in synchrony with motion-sensitized gradients. A $30-\mathrm{Hz}$ sinusoidal vibration frequency was used to maximize wave propagation into the deep regions of the brain. Tissue displacements were imaged in 3 directions at 8 time points during the sinusoidal vibration with a fastfield echo MRE sequence. ${ }^{21}$ Imaging parameters were the following: FOV $=192 \times 192 \mathrm{~mm}$, matrix $=96 \times 96,9$ sections, section thickness $=2-\mathrm{mm}, \mathrm{TR} / \mathrm{TE}=104.1 / 9.2 \mathrm{~ms}$, flip angle $=20^{\circ}$, sensitivity encoding $=1.5$ with no $k$-space reduction. Acquisition 
Internal jugular vein flow-rate

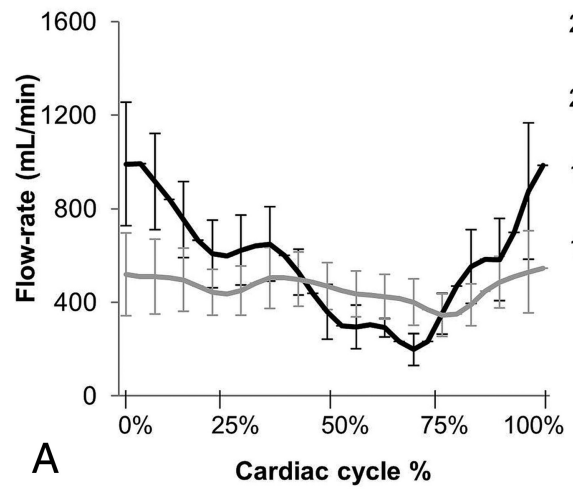

Carotid \& vertebral artery flow-rate

Cerebral aqueduct CSF velocity
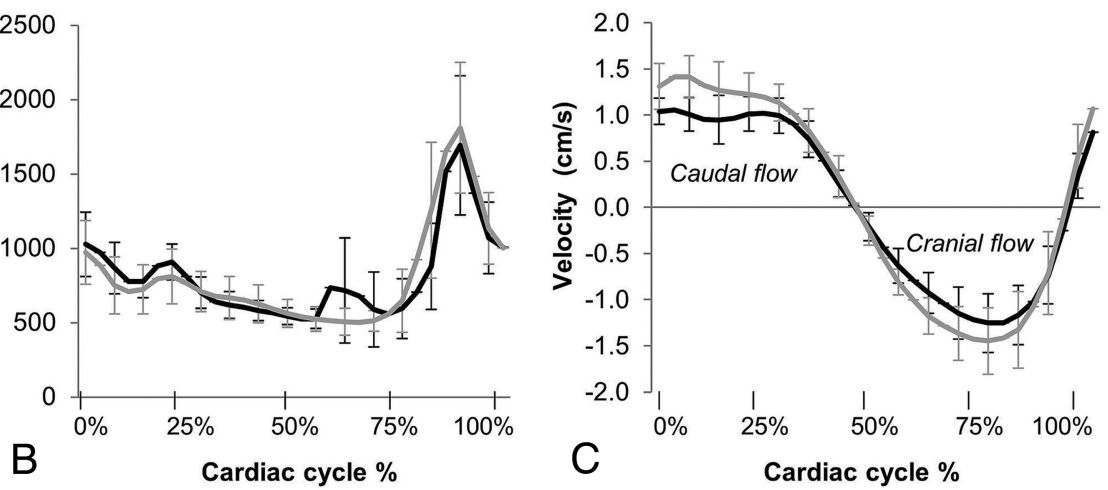

- Unrestricted flow - Jugular compression

FIG 2. Group mean flow waveforms for internal jugular vein flow $(A)$ and carotid and vertebral artery flow (B); and group mean CSF velocity waveforms through the cerebral aqueduct $(C)$. Venous flow-rate peaks are suppressed with jugular compression; however, arterial flow waveforms are unaffected. Maximal caudally directed velocity of the CSF in the aqueduct increases with jugular compression.

Table 1: Blood flow parameters

\begin{tabular}{|c|c|c|c|c|}
\hline & \multicolumn{2}{|c|}{ Internal Jugular Vein Flow } & \multicolumn{2}{|c|}{ Arterial Flow } \\
\hline & Unrestricted Flow & Jugular Compression & Unrestricted Flow & Jugular Compression \\
\hline \multicolumn{5}{|c|}{ Mean vessel area $\left(\mathrm{cm}^{2}\right)$} \\
\hline Mean & $1.17 \pm 0.54$ & $0.70 \pm 0.35$ & $1.0 \pm 0.77$ & $0.97 \pm 0.68$ \\
\hline Range & $0.40-2.18$ & $0.29-1.41$ & $-0.99-1.53$ & $-0.76-1.56$ \\
\hline$t$ test & \multicolumn{2}{|c|}{$t=3.56, P=.005^{\mathrm{a}}$} & \multicolumn{2}{|c|}{$t=0.51, P=.604$} \\
\hline \multicolumn{5}{|c|}{$\begin{array}{l}\text { Mean flow rate }(\mathrm{mL} / \mathrm{min}) \text { (caudal flow for } \\
\text { venous flow, cranial for arterial) }\end{array}$} \\
\hline Mean & $572.2 \pm 219.7$ & $460.8 \pm 202.4$ & $814.7 \pm 221.9$ & $815.3 \pm 290.6$ \\
\hline Range & $153.8-862.2$ & $135-726.4$ & $268-989.2$ & 127.7-1070 \\
\hline$t$ test & \multicolumn{2}{|c|}{$t=2.85, P=.008^{\mathrm{a}}$} & \multicolumn{2}{|c|}{$-0.01, P=.989$} \\
\hline \multicolumn{5}{|c|}{ Flow-rate amplitude (mL/min) } \\
\hline Mean & $974.1 \pm 523.6$ & $382.6 \pm 312.7$ & $1803.8 \pm 490.1$ & $1720.6 \pm 688.4$ \\
\hline Range & $198.5-1838.8$ & 56.8-1069.0 & $601.4-2290.2$ & $282.8-2721.4$ \\
\hline$t$ test & \multicolumn{2}{|c|}{$t=3.75, P=.002^{\mathrm{a}}$} & \multicolumn{2}{|c|}{$t=0.58, P=.558$} \\
\hline
\end{tabular}

time was 4 minutes. A high-resolution (matrix $=256 \times 256)$ T2-weighted image set with matching geometry was acquired.

\section{Analysis}

Vascular and CSF Flow Studies. Vascular and CSF flows were analyzed by using Segment (Academic Research Version 1.9R2455; Medviso, Lund, Sweden) following eddy current effect compensation $^{22}$ as follows:

- Mean vessel area: The mean cross-sectional area (square centimeters) of the left and right vertebral and carotid arteries, and left and right internal jugular veins.

- Mean flow rate and flow-rate amplitude: The mean blood flow rates (milliliter/minute) and the flow-rate amplitude (milliliter/minute) calculated as the difference between the maximum and minimum flow rates.

- Percentage jugular venous flow (PJVF): Flow in the internal jugular veins as a percentage of carotid and vertebral arterial inflow.

- CSF velocity maxima: The maximum velocity (centimeter/second) of CSF flowing in the caudal and cranial directions.

- Duration of caudal flow: The duration of caudally directed flow as a percentage of the cardiac cycle.
MRE. The shear storage and loss moduli, $G^{\prime}$ and $G^{\prime \prime}$, were estimated from the tissue displacements by numerically solving the governing equation for shear wave propagation through an isotropic viscoelastic material after applying the curl operator to remove the pressure term associated with compressional waves. Details of the theory and reconstruction have been described in depth previously. ${ }^{16,23,24}$

ROIs covering the whole-brain parenchyma (gray and white matter) in each MRE section were manually defined on the anatomic images by using ImageJ software (National Institutes of Health, Bethesda, Maryland) and exported to Matlab (MathWorks, Natick, Massachusetts). Sulci, gyri, and regions of CSF, such as the ventricles and adjacent pixels that could have partial volumes of CSF, were excluded from the ROIs.

\section{Statistical Analysis}

The range, mean, and SD of the flow and brain viscoelastic parameters were calculated with and without jugular compression. A paired $t$ test was used to evaluate the decrease in venous flow, increases in CSF flow, and viscoelastic parameters and to analyze differences in arterial flow and heart rate. Linear regression was used to analyze the relationships between PJVF and 
the shear storage and loss moduli and between the intrasubject change in $G^{\prime}$ and $G^{\prime \prime}$ and the maximal velocity of caudally directed CSF.

\section{Table 2: PJVF values for subjects}

\begin{tabular}{|c|c|c|}
\hline & \multicolumn{2}{|c|}{ PJVF } \\
\hline & $\begin{array}{l}\text { Unrestricted } \\
\text { Flow }\end{array}$ & $\begin{array}{c}\text { Jugular } \\
\text { Compression }\end{array}$ \\
\hline Subject 1 & $97.2 \%$ & $53.0 \%$ \\
\hline Subject 2 & $84.1 \%$ & $70.6 \%$ \\
\hline Subject 3 & $82.1 \%$ & $81.5 \%$ \\
\hline Subject 4 & $76.8 \%$ & $69.5 \%$ \\
\hline Subject 5 & $74.2 \%$ & $44.3 \%$ \\
\hline Subject 6 & $61.2 \%$ & $27.0 \%$ \\
\hline Subject 7 & $59.8 \%$ & $63.8 \%$ \\
\hline Subject 8 & $59.3 \%$ & $60.0 \%$ \\
\hline Subject 9 & $17.9 \%$ & $13.7 \%$ \\
\hline Mean & $68.1 \pm 22.7 \%$ & $53.7 \pm 21.9 \%$ \\
\hline$t$ test & $t=2.3$ & $=.019^{\mathrm{a}}$ \\
\hline \multicolumn{3}{|l|}{$\begin{array}{l}\text { Predominantly jugular flow } \\
\text { (between } 50 \% \text { and } 100 \% \text { ) }\end{array}$} \\
\hline Subjects & $8 / 9$ & $6 / 9$ \\
\hline \multicolumn{3}{|l|}{$\begin{array}{l}\text { Predominantly nonjugular } \\
\text { flow }(<50 \%)\end{array}$} \\
\hline Subjects & $1 / 9$ & $3 / 9$ \\
\hline
\end{tabular}

\section{Table 3: CSF velocity parameters}

\begin{tabular}{|c|c|c|}
\hline & \multicolumn{2}{|c|}{ Aqueductal Flow } \\
\hline & $\begin{array}{l}\text { Unrestricted } \\
\text { Flow }\end{array}$ & $\begin{array}{c}\text { Jugular } \\
\text { Compression }\end{array}$ \\
\hline \multicolumn{3}{|c|}{ Maximum caudal velocity $(\mathrm{cm} / \mathrm{s})$} \\
\hline Mean & $1.18 \pm 0.33$ & $1.53 \pm 0.42$ \\
\hline Range & $0.81-1.85$ & $1.04-2.36$ \\
\hline$t$ test & \multicolumn{2}{|c|}{$t=-4.96, P=.0004^{\mathrm{a}}$} \\
\hline \multicolumn{3}{|c|}{ Maximum cranial velocity $(\mathrm{cm} / \mathrm{s})$} \\
\hline Mean & $1.38 \pm 0.57$ & $1.62 \pm 0.62$ \\
\hline Range & $0.73-2.47$ & $0.66-2.48$ \\
\hline$t$ test & \multicolumn{2}{|c|}{$t=1.58, P=.066$} \\
\hline \multicolumn{3}{|c|}{$\begin{array}{l}\text { Duration of caudally directed flow } \\
\text { (\% cardiac cycle) }\end{array}$} \\
\hline Mean & $49.9 \pm 5.2 \%$ & $51.4 \pm 5.3 \%$ \\
\hline Range & $40.7 \%-57.7 \%$ & $42.1 \%-61.7 \%$ \\
\hline$t$ test & \multicolumn{2}{|c|}{$t=-1.0, P=.160$} \\
\hline
\end{tabular}

\section{RESULTS}

\section{Blood Flow}

Figure 2 shows the group mean flow waveforms for internal jugular venous flow (Fig $2 A$ ) and carotid and vertebral arterial flow (Fig $2 B$ ) with and without jugular compression. Jugular compression significantly reduced the mean internal jugular vein area $(t=$ $3.56, P=.005)$, with suppression of the venous flow peak following systole and a significant reduction in the mean and peak venous flow rate $(t=2.85, P=.008 ; t=3.75, P=.002)$. The mean arterial area, flow waveforms, and flow parameters were unaffected by jugular compression $(P>.05)$. Blood flow parameters and statistical results are listed in Table 1.

Table 2 contains the values of PJVF for subjects with and without jugular compression. Without compression, the internal jugular veins carried most of the outflow of cranial blood (PJVF values of $>50 \%$ ) in 8 of 9 subjects. During jugular compression, PJVF was decreased (flow was diverted to nonjugular pathways) in 7 subjects, and 3 of these had predominantly nonjugular venous drainage (PJVF of $<50 \%$ ). PJVF was reduced with neck wrapping ( $t=2.33, P=.019)$, indicating the redirection of venous blood to nonjugular vessels.

\section{CSF Flow}

Figure $2 C$ depicts the group mean cerebral aqueduct CSF flow with and without jugular compression. Corresponding flow parameters and statistical analyses are listed in Table 3.

The maximal velocity of caudally directed CSF through the aqueduct increased significantly with jugular compression $(t=-4.96, P<.001)$. Neither the maximal cranially directed velocity nor the duration of caudally directed flow was significantly changed $(P>.05)$.

Heart rates calculated from vascular data were not significantly affected by the neck wrap $(t=-0.66, P=.528)$.

\section{Viscoelasticity}

Figure 3 shows sample viscoelastic maps for shear storage and loss moduli. Table 4 contains the range, mean, SD, and statistics. Figure $4 A$ depicts the change in $\mathrm{G}^{\prime}$ and $\mathrm{G}^{\prime \prime}$ between the unrestricted and jugular compression conditions for all subjects.
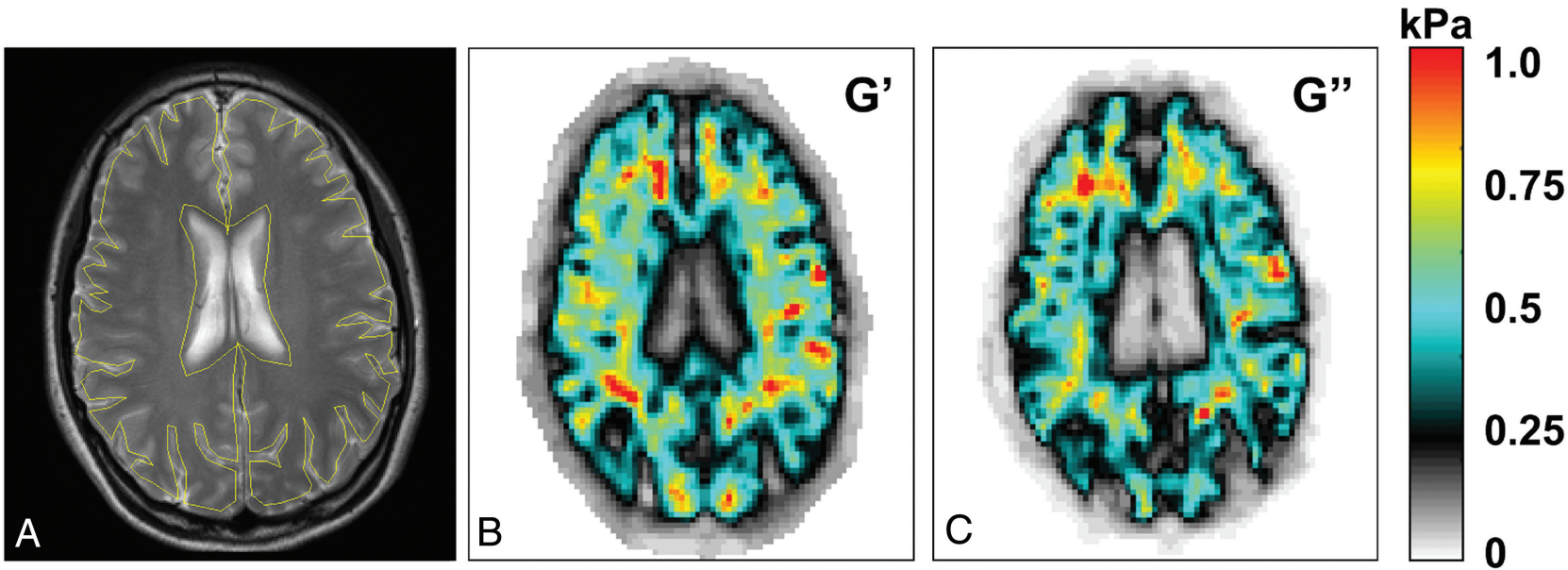

FIG 3. ROI and sample viscoelastic maps. A, Sample high-resolution anatomic image shows the ROI (yellow line). Viscoelastic property maps for $G^{\prime}(B)$ and $G^{\prime \prime}(C)$ in kilopascals. In the viscoelastic maps, the ventricles and large sulci have very low (near zero) shear moduli, indicating that they are filled with CSF, which has waterlike properties. Stiffer tissue is indicated by warmer colors, as indicated by the color bar (right). 
Contrary to our hypothesis, jugular compression did not cause an overall significant increase in either the storage or loss moduli of the brain $(t=0.167, P=.436 ; t=0.227 ; P=.413$, respectively).

Linear regression results are in Table 5 . There was no relationship between $G^{\prime}$ and $G^{\prime \prime}$ and the percentage of arterial blood draining through the internal jugular veins for unrestricted flow. However with jugular compression, both $G^{\prime}$ and $G^{\prime \prime}$ increased linearly with PJVF $\left(R^{2}=0.475, P=.04\right.$; and $R^{2}=0.449, P=.048$, respectively) (Fig 5). There was no relationship between the change in the viscoelastic properties and the change in the peak caudal CSF velocity $(P>.05)$.

\section{Subject with the Lowest Initial Brain $\mathbf{G}^{\prime}$}

Figure 4 (right) shows the CSF waveforms for 1 subject whose baseline brain stiffness $\left(G^{\prime}\right)$ was lower than that of the other subjects (identified by the black line). Jugular compression in this subject resulted in a $17 \%$ increase in the brain shear storage modulus. This was accompanied by a $61 \%$ increase in the maximal peak caudal CSF velocity and an $11 \%$ increase in the duration of caudal CSF flow. These were the largest increases of these parameters seen in any subject. This pattern was, however, not uniform across all subjects.

\section{DISCUSSION}

This study shows that brain tissue stiffness during jugular compression varies depending on whether cranial venous blood flow is maintained or diverted from the internal jugular veins during jugular compression. Specifically, during jugular compression, brain tissue viscoelastic properties (shear storage and loss moduli) increase with the percentage of cranial blood draining through the

Table 4: Elastic $\left(\mathbf{G}^{\prime}\right)$ and viscous $\left(\mathbf{G}^{\prime \prime}\right)$ mechanical properties of brain tissue

\begin{tabular}{ccc}
\hline & Unrestricted Flow & Jugular Compression \\
\hline $\mathrm{G}^{\prime}(\mathrm{kPa})$ & $0.691 \pm 0.067$ & $0.688 \pm 0.065$ \\
Mean & $0.567-0.805$ & $0.606-0.798$ \\
Range & \multicolumn{2}{c}{$t=0.17, P=.436$} \\
$t$ test & $0.587 \pm 0.052$ & $0.585 \pm 0.046$ \\
$\mathrm{G}^{\prime \prime}(\mathrm{kPa})$ & $0.482-0.662$ & $0.531-0.645$ \\
Mean & \multicolumn{2}{c}{$t=0.23, P=.413$} \\
Range & \multicolumn{2}{c}{} \\
$t$ test & \multicolumn{2}{c}{} \\
\hline
\end{tabular}

Intra-subject change in G'

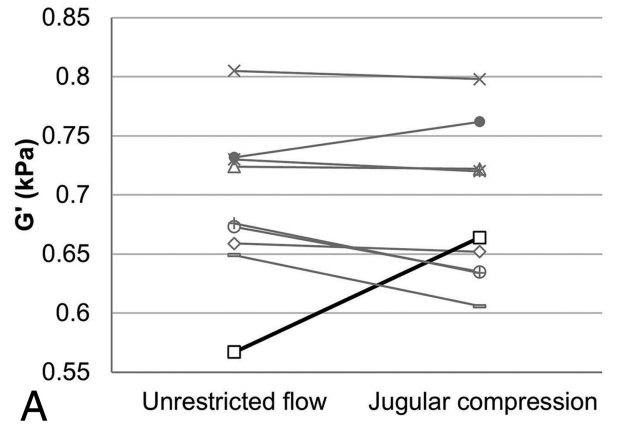

internal jugular veins - that is, brain tissue stiffness was greater in subjects who maintained jugular drainage paths despite jugular compression than in those who diverted venous blood through extrajugular pathways. CSF pulsations in the cerebral aqueduct are also affected by jugular compression, with an increase in the maximal velocity of caudally directed CSF during jugular compression. To our knowledge, this is the first study investigating the effect of jugular compression on the viscoelastic properties of the brain and intraventricular CSF dynamics.

Jugular compression is known to increase cerebral venous pressure and raise intracranial pressure due to increased resistance to outflow through the internal jugular veins. ${ }^{25-28}$ In this study, higher brain tissue shear storage and loss moduli were associated with the maintenance of predominantly jugular flow paths during jugular compression rather than diversion of blood flow to extrajugular pathways such as the vertebral, intraspinal, and deep cervical veins. Maintaining jugular venous flow during jugular compression suggests that the resistance to flow in the extrajugular pathways of these individuals was greater than that in their compressed internal jugular veins. Higher overall cerebral venous pressures likely result in these subjects having increased forces applied to the brain tissue. Conversely, internal jugular vein flow not decreasing as a proportion of total cranial outflow (in 2/9 subjects) suggests that even after compression, the internal jugular vein remained a low-resistance pathway. Because brain tissue stiffness increases with compression due to its nonlinear viscoelastic behavior, ${ }^{29-31}$ it is probable that the increasing shear

Table 5: Linear regression coefficients for the relationships between PJVF and $G^{\prime}$ and $G^{\prime \prime}$ with unrestricted flow and with jugular compression, and change in mean $\mathbf{G}^{\prime}, \mathbf{G}^{\prime \prime}$, and maximal caudal CSF velocity

\begin{tabular}{lll}
\hline & $\boldsymbol{R}^{2}$ & $\boldsymbol{P}$ \\
\hline G' $^{\prime}$ and PJVF, unrestricted flow & 0.136 & .330 \\
$\mathrm{G}^{\prime}$ and PJVF, jugular compression & 0.475 & $.040^{\mathrm{a}}$ \\
$\mathrm{G}^{\prime \prime}$ and PJVF, unrestricted flow & 0.151 & .301 \\
$\mathrm{G}^{\prime \prime}$ and PJVF, jugular compression & 0.449 & $.048^{\mathrm{a}}$ \\
\% Change G' and \% change in max. caudal & 0.412 & .063 \\
$\quad$ CSF velocity & & \\
\% Change G" and \% change in max. caudal & 0.171 & .268 \\
$\quad$ CSF velocity & & \\
\hline Note:-max. indicates maximum. & & \\
${ }^{a} P<.05$, paired $t$ test. &
\end{tabular}

\section{CSF velocity in subject with lowest initial G'}

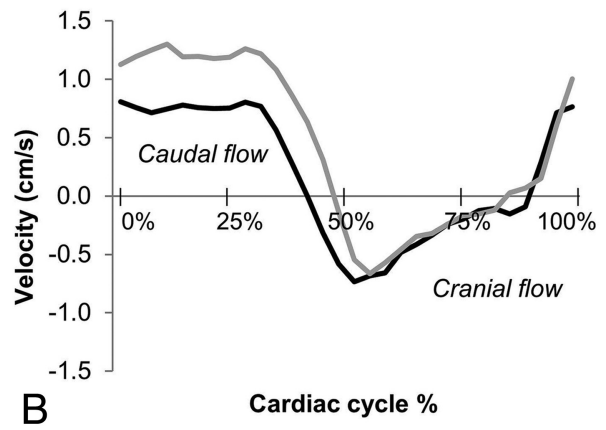

- Unrestricted flow - Jugular compression

FIG 4. $A$, Individual subject change in $\mathrm{G}^{\prime}$ in unrestricted and jugular compression conditions for all subjects. $B$, Cerebral aqueduct CSF velocity waveforms for a single subject are depicted by the black line in $A$. In this subject, the $17 \%$ increase in $\mathrm{G}^{\prime}$ with jugular compression was related to a $61 \%$ increase in the maximal caudal CSF velocity and an $11 \%$ longer caudal-flow duration. 

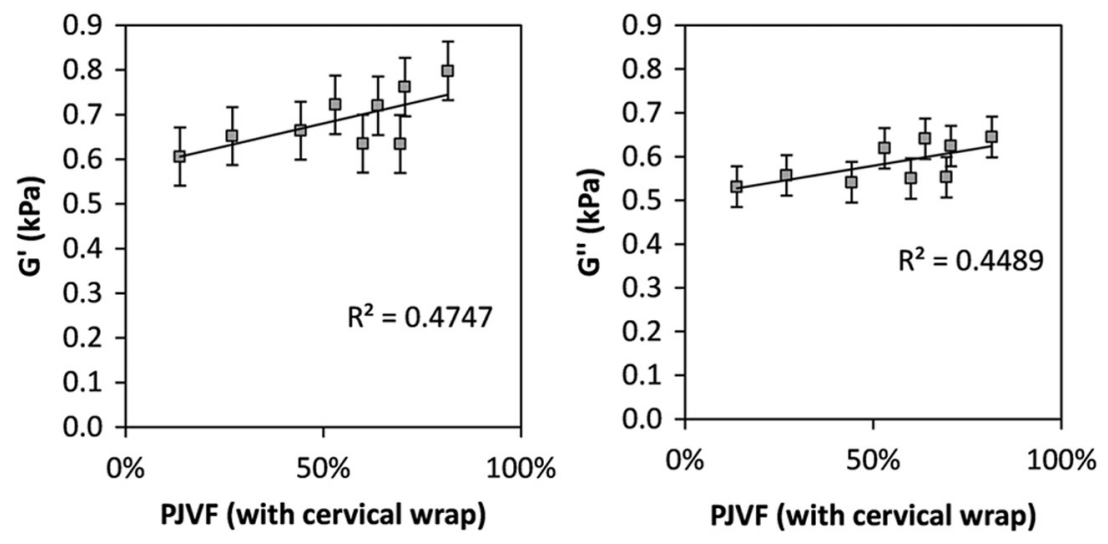

FIG 5. The relationship between shear moduli and the percentage of jugular vein flow with the cervical wrap in place. Storage modulus $\left(\mathrm{G}^{\prime}\right.$, left) and loss modulus $\left(\mathrm{G}^{\prime \prime}\right.$, right). Error bars are standard error of the mean in both panels. Both storage and loss moduli are significantly correlated with the percentage of jugular vein flow with the cervical wrap in place $(P<.05)$.
Limitations of this study include performing our measurements on healthy volunteers, who may not exhibit the same physiologic responses (such as cerebral vascular autoregulation) as patients with SILPAH. In addition, we did not measure intracranial or venous pressures, so we can only speculate about changes in these parameters with jugular compression. However, this study demonstrates the feasibility of using MRE in clinical studies to investigate the biomechanical mechanisms of brain disorders and its potential as an adjunct to phasecontrast MR imaging in assessing patients with CSF flow disorders. storage and loss moduli measured with increasing jugular flow percentage are the result of higher pressure on the brain tissue from the cerebral veins. Note that the absolute changes in brain stiffness observed here in healthy volunteers are small and may not have clinical significance.

In this study, CSF was expelled more rapidly from the cerebral aqueduct with jugular compression. Similar findings have been reported in the cervical subarachnoid space in subjects with primarily jugular venous flow paths before compression. ${ }^{14} \mathrm{CSF}$ pulsations in the brain are the result of the movement of cerebral blood within the rigid intracranial system. ${ }^{32}$ The influx of arterial blood following systole causes venous blood to be expelled from the cranium and CSF to flow into the spinal subarachnoid space. Jugular compression restricts venous outflow, limiting cranial space for arterial expansion and promoting more rapid expulsion of CSF from the ventricles.

Pang and Altschuler ${ }^{9}$ and Rekate $^{8}$ describe SILPAH as resulting from changes to the viscoelastic properties of the brain. Rekate refers to the condition as "floppy brain syndrome," describing jugular compression as a means of increasing brain "turgor," defined as the ability of the brain tissue to resist distortion. ${ }^{8}$ "While the hypothesis of lower brain tissue stiffness in patients with SILPAH $^{4,6,8}$ has not been tested, 1 subject in our cohort who initially had lower brain stiffness than the rest of the group may lend support to the idea that jugular compression may "normalize" brain viscoelasticity. Jugular compression in this subject resulted in the largest increases in brain viscoelasticity and CSF velocity of any subject. If patients with SILPAH have lower brain stiffness than healthy subjects, it is possible that the stiffening of the brain tissue through the use of the neck wrap is enough to encourage expulsion of excess CSF from the ventricles, restoring normal ventricular size. This remains to be determined in patients with SILPAH, but this study suggests such research is feasible.

MRE has not been previously used to examine changes in brain stiffness in SILPAH or as a result of jugular vein compression. The lower absolute shear modulus values obtained in this study compared with previous studies ${ }^{16,19}$ are due to the lower vibration frequency, because brain tissue shear moduli increase with frequency. ${ }^{31}$ The lower frequency was chosen to maximize wave penetration into the deep brain because higher frequencies are more rapidly attenuated in brain tissue.

\section{CONCLUSIONS}

In healthy subjects, those who do not divert venous blood through extrajugular pathways during jugular compression have higher brain stiffness than those who do, likely as a result of increased neurovascular pressure. While this study did not confirm our hypothesis that jugular compression increases brain viscoelasticity in all subjects, it has shown that the MRE technique can measure changes in brain tissue viscoelasticity in this context and suggests that MRE could be a useful tool to measure brain mechanical properties of patients with SILPAH, including during jugular compression. These findings may help elucidate the mechanisms of SILPAH and the means by which jugular compression improves symptoms, and they may also be useful for other conditions in which jugular flow is restricted.

\section{ACKNOWLEDGMENTS}

We thank the staff of the NeuRA Clinical Research Imaging Centre for their help in this study and also Dr Harold Rekate for stimulating discussions regarding this study.

Disclosures: Alice Hatt—RELATED: Grant: Ronald Geoffrey Arnott Foundation. ${ }^{*}$ Lynne E. Bilston—RELATED: Grant: Ronald Geoffrey Arnott Foundation, ${ }^{*}$ National Health and Medical Research Council of Australia*; UNRELATED: Consultancy: Linguaflex LLC; Grants/Grants Pending: National Health and Medical Research Council,* Australian Research Council,* Comments: I have research grant funding from these councils; Travel/Accommodations/Meeting Expenses Unrelated to Activities Listed: Université de Technologie de Compiègne, France, Comments: travel expenses and honorarium to attend the Scientific Advisory Committee for UTC Laboratory of Excellence in System of Systems, 2013 and 2014. *Money paid to the institution.

\section{REFERENCES}

1. Alperin N, Lee SH, Sivaramakrishnan A, et al. Quantifying the effect of posture on intracranial physiology in humans by MRI flow studies. J Magn Reson Imaging 2005;22:591-96

2. Laughlin S, Macgowan CK, Traubici J, et al. No evidence for impairment of venous hemodynamics in children or young adults with pediatric-onset multiple sclerosis. AJNR Am J Neuroradiol 2013;34:2366-72

3. Hamilton MG, Price AV. Syndrome of inappropriately low-pressure acute hydrocephalus (SILPAH). Acta Neurochir Suppl 2012;113:155-59

4. Rekate HL, Nadkarni TD, Wallace D. The importance of the cortical 
subarachnoid space in understanding hydrocephalus. J Neurosurg Pediatr 2008;2:1-11

5. Wait SD, Ponce FA, Killory BD, et al. Neuroleptic malignant syndrome from central nervous system insult: 4 cases and a novel treatment strategy. J Neurosurg Pediatr 2009;4:217-21

6. Filippidis AS, Kalani MY, Nakaji P, et al. Negative-pressure and lowpressure hydrocephalus: the role of cerebrospinal fluid leaks resulting from surgical approaches to the cranial base. J Neurosurg 2011;115:1031-37

7. Kalani MY, Turner JD, Nakaji P. Treatment of refractory lowpressure hydrocephalus with an active pumping negative-pressure shunt system. J Clin Neurosci 2013;20:462-66

8. Rekate HL. Recent advances in the understanding and treatment of hydrocephalus. Semin Pediatr Neurol 1997;4:167-78

9. Pang D, Altschuler E. Low-pressure hydrocephalic state and viscoelastic alterations in the brain. Neurosurgery 1994;35:643-56; discussion 655-56

10. Owler BK, Jacobson EE, Johnston IH. Low pressure hydrocephalus: issues of diagnosis and treatment in five cases. $\mathrm{Br} J$ Neurosurg 2001;15:353-59

11. Lesniak MS, Clatterbuck RE, Rigamonti D, et al. Low pressure hydrocephalus and ventriculomegaly: hysteresis, non-linear dynamics, and the benefits of CSF diversion. Br J Neurosurg 2002;16:555-61

12. Clarke MJ, Maher CO, Nothdurft G, et al. Very low pressure hydrocephalus: report of two cases. J Neurosurg 2006;105:475-78

13. Rekate $\mathrm{H}$. Brain turgor $(\mathbf{K b})$ : intrinsic property of the brain to resist distortion. Pediatr Neurosurg 1992;18:257-62

14. Bhadelia RA, Bogdan AR, Wolpert SM. Cerebrospinal fluid flow waveforms: effect of altered cranial venous outflow-a phasecontrast MR flow imaging study. Neuroradiology 1998;40:283-92

15. Muthupillai R, Lomas DJ, Rossman PJ, et al. Magnetic resonance elastography by direct visualization of propagating acoustic strain waves. Science 1995;269:1854-57

16. Green MA, Bilston LE, Sinkus R. In vivo brain viscoelastic properties measured by magnetic resonance elastography. NMR Biomed 2008;21:755-64

17. Hamhaber U, Sack I, Papazoglou S, et al. Three-dimensional analysis of shear wave propagation observed by in vivo magnetic resonance elastography of the brain. Acta Biomater 2007;3:127-37

18. Zhang J, Green MA, Sinkus R, et al. Viscoelastic properties of human cerebellum using magnetic resonance elastography. J Biomech 2011;44:1909-13

19. Streitberger KJ, Wiener E, Hoffmann J, et al. In vivo viscoelastic properties of the brain in normal pressure hydrocephalus. $N M R$ Biomed 2011;24:385-92

20. Freimann FB, Streitberger KJ, Klatt D, et al. Alteration of brain viscoelasticity after shunt treatment in normal pressure hydrocephalus. Neuroradiology 2012;54:189-96

21. Garteiser P, Sahebjavaher RS, Ter Beek LC, et al. Rapid acquisition of multifrequency, multislice and multidirectional MR elastography data with a fractionally encoded gradient echo sequence. $N M R$ Biomed 2013;26:1326-35

22. Heiberg E, Sjögren J, Ugander M, et al. Design and validation of Segment-freely available software for cardiovascular image analysis. BMC Med Imaging 2010;10:1

23. Sinkus R, Lorenzen J, Schrader D, et al. High-resolution tensor MR elastography for breast tumour detection. Phys Med Biol 2000;45: 1649-64

24. Sinkus R, Tanter M, Xydeas T, et al. Viscoelastic shear properties of in vivo breast lesions measured by MR elastography. Magn Reson Imaging 2005;23:159-65

25. Toung T, Ngeow YK, Long DL, et al. Comparison of the effects of positive end-expiratory pressure and jugular venous compression on canine cerebral venous pressure. Anesthesiology 1984;61:169-72

26. Hulme A, Cooper R. The effects of head position and jugular vein compression (JVC) on intracranial pressure (ICP): a clinical study. In: Beks JW, Bosch DA, Brock M, eds. Intracranial Pressure III. Berlin: Springer-Verlag; 1976:259-63

27. Grady MS, Bedford RF, Park T. Changes in superior sagittal sinus pressure in children with head elevation, jugular venous compression, and PEEP. J Neurosurg 1986;65:199-202

28. Ho AM, Fung KY, Joynt GM, et al. Rigid cervical collar and intracranial pressure of patients with severe head injury. I Trauma 2002;53:1185-88

29. Cheng S, Bilston LE. Unconfined compression of white matter. J Biomech 2007;40:117-24

30. Bilston LE, Liu Z, Phan-Thien N. Large strain behaviour of brain tissue in shear: some experimental data and differential constitutive model. Biorheology 2001;38:335-45

31. Cheng S, Clarke EC, Bilston LE. Rheological properties of the tissues of the central nervous system: a review. Med Eng Phys 2008;30: $1318-37$

32. Greitz D, Wirestam R, Franck A, et al. Pulsatile brain movement and associated hydrodynamics studied by magnetic resonance phase imaging: the Monro-Kellie doctrine revisited. Neuroradiology 1992;34:370-80 